\title{
Validity of Arm-Span to estimate height in older adults: a secondary analysis of a Colombian cohort, SABE Bogotá study
}

Miguel Germán Borda Borda ( $\nabla$ mmborda@gmail.com )

Instituto de envejecimiento, Facultad de Medicina, Pontificia Universidad Javeriana https://orcid.org/0000-0001-5832-0603

Carlos Cano-Gutierrez

Pontificia Universidad Javeriana

María Juliana Lozano

Pontificia Universidad Javeriana

Samir Aruachan

Pontificia Universidad Javeriana

Nicolás Castellanos-Perilla

Pontificia Universidad Javeriana

Mario Ulises Pérez-Zepeda

Instituto Nacional de Geriatria

Carlos A. Reyes-Ortiz

University of Texas Health Northeast

Research article

Keywords: Aged, Anthropometry, Arm span length, Body Height, Body Mass Index, Nutrition Assessment

Posted Date: July 3rd, 2019

DOI: https://doi.org/10.21203/rs.2.10875/v1

License: () (7) This work is licensed under a Creative Commons Attribution 4.0 International License. Read Full License 


\section{Abstract}

Background Body composition and height changes with aging which brings challenges in order to obtain accurate measures in this population, height measurement is of great importance both in nutritional and clinical assessment in the elderly, and it has been widely used for obtaining values such as body mass index, the aim of this study was to assess the validity of arm span to estimate height in Colombian older adults. Methods This is a secondary analysis of the SABE-Bogota study (2012); which is a cross-sectional survey conducted in older adults over the age of 60 ; with a final sample $n=1,436$. Spearman `s Rho correlation coefficient was used to assess concurrent validity, while limits of agreement were set through Bland-Altman plots. Criterion validity was performed comparing face-to-face measured height with arm-span estimated height with linear regressions (R2 and SEE). Results There was a significant correlation between measured height and arm span estimated height of $0.856(\mathrm{Cl} 95 \% 0.842-0.870 ; \mathrm{p}<0.0001)$. Limits of agreement ranged between -7.65 and $11.14 \mathrm{~cm}$. R2values ranged between 0.3 and 0.8 , SEE was lower in males between 60 and 79 years of age. Conclusions Alternatives to estimate height in older adults are necessary. Our results suggest that the arm span is a valid measure for the estimation of measured height in Colombian older adults.

\section{Background}

According to the World Health Organization (WHO), the proportion of 60 -year or older adults worldwide will increase from 12 to $22 \%$ between 2015 and 2050 (1). As a consequence of these demographic changes, strains in health services are expected; mainly due to the higher prevalence of chronic diseases in this age group (2). In fact, developing countries will face the combination of scarce specialized resources (e.g., geriatricians, nutritionists specialized in aging, gerontologists, etc.) and accelerated aging, which will further burden their health systems (3). In particular, Latin America \& the Caribbean is one of the regions with the fastest population aging rates; the proportion of elderly individuals is expected to increase up to 82 percent from year 2000 to 2025 (4). In particular, those professionals caring for the nutrition of the older adult population, face numerous challenges, such as the lack of accurate measurements for parameters that could have been impacted by aging (i.e., body height).

Body composition is characterized by dynamic changes along the course of life. Aging is not an exception; older adults display changes that could turn into diseases requiring intervention. For example, a decline in bone mineral density (BMD) commonly results in pathologies such as osteoporosis (5). This lower BMD prompts adequate therapy in order to avoid adverse outcomes (e.g. hip fracture). However, it also leads to additional problems such as difficulties for height measurement (6)(7). There is a decrease of about 5 to 8 centimeters $(\mathrm{cm})$ of height in an 80 -year older adult (compared to their maximum height), due to a decrease in vertebral bodies, vertebral discs, increase in dorsal kyphosis and arch loss. (8-10)

Height is of paramount importance in clinical settings because of its multiple uses and significance in different every-day older adult care situations such as the nutritional assessment, which is relevant for geriatric medicine daily practice. However, it is difficult to rely on height measurements in some subjects, since in addition to lower BMD they may have further comorbidities, such as: contractures, quadriplegia, paraplegia, alterations of consciousness, pain, and weakness, among others. The latter may make height measurements less reliable $(11,12)$.

Surrogates of height have displayed valid results when compared to the actual measured height. However, estimations for this particular purpose should be population-specific, since previous reports point to the fact that anthropometric measurements may vary according to ethnicity, lifestyle, economics and environmental factors $(13,14)$. In particular, previous studies carried out in Latin American populations have addressed the validity of knee-height; finding that equations derived from this measurement are valid for this group of older adults $(15,16)$. However, knee-height has a number of limitations; for example, the impossibility to be measured in amputated individuals - a common condition in older adults (17). Moreover, knee-height derived equations have shown to underestimate $\mathrm{BMI}$ in women (18).

Therefore, having alternatives for height measurement with population-specific validity; is certainly an increasing need for the appropriate nutrition assessment of older individuals, worldwide. To the best of our knowledge, there are no reports on the validity of arm-span derived height (ASDH) for the estimation of measured height $(\mathrm{MH})$ in Latin American older adults, and in particular from Colombia. Therefore, the aim of this study is to assess the validity of ASDH in estimating $\mathrm{MH}$ in Colombian older adults.

\section{Methods}

\section{Design and Sampling}

This is a secondary analysis of the Survey on Health, Well-Being, and Aging in Latin America and the Caribbean in Bogotá, Colombia (SABE-B) study. In brief, this is a cross-sectional study, with a representative sample of 60-year or older adults from Bogotá -capital city of Colombia- with a total of 2,000 individuals.

The questionnaire used in the SABE-B was derived from the original SABE study, which was previously conducted in eight Latin American capital cities. The instrument was modified and adapted to Colombia`s context, having added other relevant topics for the region, such as violence. Further description on the aim and design of the SABE-B study is available elsewhere (19).

\section{Anthropometric Measurements}

In addition to the questionnaire, some anthropometric measurements were also available from the SABE-B, including MH and arm-span. Height was measured $(\mathrm{cm})$ with a stadiometer, installed at a $90^{\circ}$ angle between the wall and the floor, by using a graded tape placed $0 \mathrm{~cm}$ from the ground and then fixed to the wall. Individuals were asked to be in an upright position with their heels together, standing against the wall. An imaginary line was drawn (Frankfurt plane) from the upper edge of the ear canal to the base of the orbit, parallel to the stadiometer forming a right angle with the wall; in order to standardize head's position. The 
measurement was taken from the tip of the head to the floor. An average of three measurements was used for analyses. The arm span was taken as the distance from the third finger of the left hand to the third finger of the right hand. The older adult in a sitting position, was asked to stretch her arms at a $90^{\circ}$ along a previously placed metric tape. This tape was stuck to the wall and parallel to the floor. Also, the average of three measurements (cm) was used for analysis.

\section{Other Variables}

Age in years was available as a continuous variable and was further classified into the following categories: 60-64, 65-69, 70-74, 75-79 and $\geq 80$. In addition, sex was also used to stratify all the analyses.

\section{Statistical Analysis}

Descriptive statistics stratified by age group and sex were performed both for MH and arm-span. We present means and standard deviations (SD) for each group. Mean differences between $\mathrm{MH}$ and arm span were tested through paired t-tests.

In order to assess concurrent validity, a Spearman's Rho correlation between both measurements, and scatter plots were performed. We assessed the limits of agreement with a Bland-Altman plot used to graphically illustrate the limits between $\mathrm{MH}$ and ASDH. Linear regression analysis was carried out to derive predictive equations for the estimation of height with $\mathrm{MH}$ as the dependent variable and ASDH as the independent variable. Finally, $\mathrm{R}^{2}$ and standard error

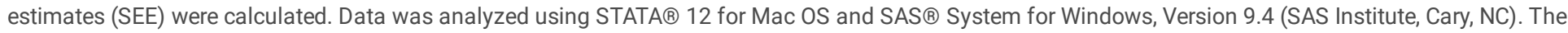
statistical significance level was set at $p<0.05$, for all the estimates.

\section{Ethical Issues}

All study participants signed an informed consent form. The informed consent form, the instruments and all of the study materials were approved by the Institutional Review Boards of Research and Ethics Committee at Pontifical Xavierian University and are according to the latest version of the Helsinki declaration.

\section{Results}

From the original 2,000 participants, a total of 1,436 had complete information on height and arm span. The mean age was 71.17 years, and $64 \%$ were female.

Table 1 shows the mean differences between $\mathrm{MH}$ an $\mathrm{ASDH}$ among all groups, showing a statistically significant difference ( $\mathrm{p}<0.001)$ in values of $1.9 \pm 5.2$ for male and $1.7 \pm 4.4$ for females within the total group.

Regarding correlations, for males, the Spearman's Rho ranged between 0.76 in the $70-74$ age group and 0.90 in the $\geq 80$ age group. For the female group, the Spearman

sRhoran $\geq$ dbetween $0.68 \in$ the $75-79 a \geq$ group and $0.84 \in$ the $65-69$ and $70-74 a \geq$ groups $($ Tab $\leq 2)$. Inthe $\rightarrow$ talgroupanaly s Rho correlation of 0.84 for males and 0.80 for females (Figure 1). All of the correlations were statistically significant.

Figure 1. Sex-stratified Scatter-plot Between Arm Span and Height, showing Spearman`s Rho

The slopes (regression beta coefficients) for ASDH ranged between 0.5 and 0.8 (Table 2). The $\mathrm{R}^{2}$ ranged between 0.3 and 0.8 across age groups and gender, and in the total sample, it was 0.6 . Females between ages $60-74$ as well as males between ages 60-64 and 75-79 displayed lower SEE values suggesting less measurement error. All regression estimates were significant.

Figure 2. Bland-Altman Plot for Height and Arm Span

In Figure 2, Bland-Altman analysis indicates that the $95 \%$ limits of agreement between the two methods ranged between -7.65 and $11.14 \mathrm{~cm}$ (mean difference $1.74 \mathrm{~cm}, \mathrm{SD}=4.70)$. The height tends to be overestimated $(>10 \mathrm{~cm}$ in the higher limit).

\section{Discussion}

A number of measurements are currently available to assess nutrition in older adults. Some challenges are posed by changes in body composition in older adults, resulting in some difficulties - both technical and interpretative- when using common tools for this matter. (13) The clinical relevance of having an accurate parameter that reflects the underlying nutrition status is depicted in conditions such as malnutrition; a well-identified issue leading to poor prognosis (20) (21).

We analyzed the validity of ASHD in estimating $\mathrm{MH}$ in different age and sex groups of Colombian older adults. The correlation for the whole sample was 0.856 ( $\mathrm{Cl} 95 \%$ 0.842-0.870; $\mathrm{p}<0.0001)$, which is consistent with previous studies $(6,22)$. To the best of our knowledge, this is the first work to report ASHD in Latin American older adults. Having local evidence is necessary since body composition has shown to vary across different populations (23), and proper validation process are advisable for specific groups of older adults. 
As for our results, ASDH is a valid measurement for the estimation of $\mathrm{MH}$ in Colombian older adults, with appropriate limits of agreement. This opens the door for clinicians, in order for them to have an alternative when height cannot be accurately measured or when the patient's conditions do not allow height measurement in a standing position; particularly in those patients with lower limb amputation. In fact, some authors accept the ASDH as a measure in some clinical situations where measuring height is difficult. For instance, with aging, where height tends to decrease while arm span remains unchanged (6). This approach is useful as well for research settings, allowing to have more accurate measurements in older populations.

Due to progressive height loss, ASDH has been evaluated for estimating BMI in older adults, $(24,25)$ in addition to other composite indexes (e.g., skeletal muscle index). Previous studies have shown that ASDH is an accurate surrogate for $\mathrm{MH}$ in children and adults $(22,24,25)$. For example, regarding the comparison of $\mathrm{MH}$ with $\mathrm{ASDH}$, a study carried out in India showed that ASDH estimated better BMI when compared to $\mathrm{MH}$, which resulted in an overestimation of the BMI (mean difference of $10.8 \mathrm{~cm}$ in men and $9.2 \mathrm{~cm}$ in women). The latter demonstrates than ASDH is a valid alternative to MH for calculation of BMI among older adults (25). Moreover, another study in Malawi reports a mean difference of $9.9 \pm 4.9 \mathrm{~cm}$ for females and $11.6 \pm 4.4$ for males between $\mathrm{MH}$ and $\mathrm{ASDH}$ with a correlation of 0.871 for males and 0.815 for females, showing that ASDH is a good surrogate for MH (22). In addition to the utility for assessing nutritional status, other measurements requiring height adjustment have also shown similar results using ASDH. For example, it has been seen in predicted values for calculating FVC and VEF 1 for spirometry; where the predicted values were lower if measured with ASDH compared to MH. Thus, presenting worse lung function and severity disease when measured through the ASDH (26), prompting to a more precise treatment of these individuals.

Our study has some limitations. As a cross-sectional study, there is no certainty about true height loss, a longitudinal analysis would be more appropriate for this matter. Anthropometric measurements may have evaluator related biases and limitations in persons with joint pain or mobility problems. Compared to the subjects who remained in the study, those who were excluded (564) were significantly older, but there were no differences by sex. Thus, our results may apply less to the very old aged group. The sample had loss of information. In order to assess the potential impact of these missing values, comparisons of age and sex between included and non-included older adults were performed, showing no statistical difference between groups. In our study it was not possible to differentiate between rural and urban areas. However, other studies with the same characteristics in Colombia have not found significant anthropometric differences between these areas (27). Finally, the local nature of our sample makes it difficult to generalize our results.

It is widely known that the Latin American population is constituted from a mix of several ethnic origins and this fact makes them unique. Specific information on how to assess nutrition in this group narrows the knowledge gap on this topic. The SABE-Bogota sample covers a representative sample of Bogotá which is the capital of Colombia. Bogotá is recognized for being a multi-cultural and multi-ethnical city, since during the last decades massive migration from different regions in all the country occurred, due to forced displacement and need of people for better opportunities. However, most of the people in the sample recognize themselves as a non-particular race $92.9 \%$, followed by African descendent $3.1 \%$ and indigenous $2.1 \%$.

Our study has several advantages, anthropometric measurements like height and arm-span were taken three times and its average was used in our analysis, lowering the risk for measurement bias; in concordance with other studies we show that ASDH is a valid measurement to estimate MH, with appropriate limits of agreement. Our results offer a new alternative when height cannot be accurately measured or when the subject's conditions do not allow height measurement in a standing position.

\section{Conclusions}

Previous works have addressed alternatives for height estimation in older adults Latin America $(16,18)$, however this work is novel regarding the usage of arm span for estimating height in Colombian older adults. Having local evidence is necessary, since body composition varies among populations and ethnical groups (28). Therefore, these results can be of both clinical and research significance. Surrogates to MH should be studied in Latin America countries, our results suggest that the ASDH is a valid measure for the estimation of $\mathrm{MH}$ in Colombian older adults Finally, further research should aim at exploring ASDH and $\mathrm{MH}$ relationship in other Latin American countries $(17,21,13)$.

\section{Abbreviations}

WHO: World Health Organization; BMD: Bone mineral density; CM: Centimeters; MH: Measured height; SABE-B: Survey on Health, Well-Being, and Aging in Latin America and the Caribbean in Bogotá, Colombia; SD: Standard deviations; SEE: standard error estimates.

\section{Declarations}

\section{Ethics approval and consent to participate}

The Institutional Review Boards of Research and Ethics Committee of the Pontifical Xavierian University approved this study. The rights of human participants were protected.

\section{Consent for publication}

All the participants signed an informed consent to participate in the study. The consent and all the formats and documents used in the study were approved by the Research and Ethics Committee of the Pontifical Xavierian University, Bogotá.

\section{Availability of data and material}


The SABE Bogotá survey dataset used for this study, is available upon request to the Pontifical Xavierian University.

\section{Competing interests}

The authors declare they have no competing interests.

\section{Funding}

This work was funded by the Administrative Department of Science, Technology and Innovation, Colciencias, under the grant 120354531692.

\section{Author's contribution}

MGB designed the study and performed the statistical analysis, CCG supervised the study, contributed to the discussion and reviewed the manuscript, MJL contributed to the writing of the background, SA contributed to the writing of the results, NCP contributed to the literature review, writing of the abstract, results and discussions as well to the elaboration of tables, MUPZ supervised the accuracy of statistical analysis, CARO contributed to supervision of statistical analysis and figure and plot elaboration. All authors revised and approved the manuscript in its final form.

\section{Acknowledgements}

We thank to all the members of the student research group: Semillero de Neurociencias y Envejecimiento from the Pontifical Xavierian University, Bogotá Colombia.

\section{References}

1. World Health Organization. Global action plan for the prevention and control of noncommunicable diseases: 2013-2020. [Internet]. 103 p. Available from: http://www.who.int/nmh/publications/ncd-action-plan/en/

2. Cesari M, Marzetti E, Thiem U, Pérez-Zepeda MU, Abellan Van Kan G, Landi F, et al. The geriatric management of frailty as paradigm of "The end of the disease era." Eur J Intern Med; 31:11-4. Available from: http://www.ncbi.nlm.nih.gov/pubmed/26997416

3. Gutiérrez-Robledo LM. Looking at the Future of Geriatric Care in Developing Countries. J Gerontol Med Sci Am. 2002;57(3):162-7.

4. Wong R, Palloni A. Aging in Mexico and Latin America. In: International Handbook of Population Aging [Internet]. Dordrecht: Springer Netherlands; 2009. p. 231-52. Available from: http://link.springer.com/10.1007/978-1-4020-8356-3_11

5. He H, Liu Y, Tian Q, Papasian CJ, Hu T, Deng HW. Relationship of sarcopenia and body composition with osteoporosis. Osteoporos Int. 2016;27(2):473-82.

6. Villaverde-Gutiérrez C, Sánchez-López MJ, Ramirez-Rodrigo J, Ocaña-Peinado FM. Should arm span or height be used in calculating the BMI for the older people? Preliminary results. J Clin Nurs [Internet]. 2015 Mar 1;24(5-6):817-23. Available from: http://doi.wiley.com/10.1111/jocn.12744

7. Dey DK, Rothenberg E, Sundh V, Bosaeus I, Steen B. Height and body weight in the elderly. I. A 25-year longitudinal study of a population aged 70 to 95 years. Eur J Clin Nutr [Internet]. 1999 Dec; 53(12):905-14. Available from: http://www.ncbi.nlm.nih.gov/pubmed/10602346

8. Kim KH, Park JY, Kuh SU, Chin DK, Kim KS, Cho YE. Changes in Spinal Canal Diameter and Vertebral Body Height with Age. Yonsei Med J. 2013 Nov; 54(6):1498. Available from: http://www.ncbi.nlm.nih.gov/pubmed/24142657

9. St-Onge M-P, Gallagher D. Body composition changes with aging: The cause or the result of alterations in metabolic rate and macronutrient oxidation? Nutrition [Internet]. 2010 Feb; 26(2):152. Available from: http://www.ncbi.nIm.nih.gov/pubmed/20004080

10. Going S, Williams D, Lohman T. Aging and body composition: biological changes and methodological issues. Exerc Sport Sci Rev [Internet]. 1995; 23:41158. Available from: http://www.ncbi.nlm.nih.gov/pubmed/7556359

11. Becerra F. Current trends in antropometric evaluation of the elder. Rev la Fac Med. 2006;54(4):283-9.

12. Kuczmarski MF, Kuczmarski RJ, Najjar M. Descriptive Anthropometric Reference Data for Older Americans. J Am Diet Assoc [Internet]. 2000 Jan;100(1):59-66. Available from: http://www.ncbi.nlm.nih.gov/pubmed/10646006

13. de Lucia E, Lemma F, Tesfaye F, Demisse T, Ismail S. The use of armspan measurement to assess the nutritional status of adults in four Ethiopian ethnic groups. Eur J Clin Nutr [Internet]. 2002 Feb 20; 56(2):91-5. Available from: http://www.ncbi.nlm.nih.gov/pubmed/11857041

14. Quanjer PH, Mazicioglu MM. All-age relationship between arm span and height in different ethnic groups. Eur Respir J. 2014;44(4):905-12.

15. García-Peña C, Pérez-Zepeda MU. Validity of knee-estimated height to assess standing height in older adults: A secondary longitudinal analysis of the Mexican health and aging study. J Nutr Health Aging. 2017 Mar 17; 21(3):262-5. Available from: http://www.ncbi.nlm.nih.gov/pubmed/28244564

Page 5/9 
16. Palloni A, Guend A. Stature Prediction Equations for Elderly Hispanics in Latin American Countries by Sex and Ethnic Background. J Gerontol Med Sci Am. 2005;60(6):804-10.

17. Weinbrenner T, Vioque J, Barber X, Asensio L. Estimation of height and body mass index from demi-span in elderly individuals. Gerontology. 2006;52(5):275-81.

18. Fogal AS, Castro C, Priore SE. Stature estimation using the knee height measurement amongst Brazilian elderly. Nutr Hosp. 2015;31(2):829-34.

19. Albala C, Lebrão ML, León Díaz EM, Ham-Chande R, Hennis AJ, Palloni A, et al. The Health, Well-Being, and Aging (\&quot;SABE\&quot;) survey: methodology applied and profile of the study population. Rev Panam Salud Pública. 2005;17(5-6):307-22. Available from: http://www.scielosp.org/scielo.php? script=sci_arttext\&pid=S1020-49892005000500003\&lng=es\&nrm=iso\&tlng=es

20. Evans C. Malnutrition in the Elderly: A Multifactorial Failure to Thrive. Available from: https://www.ncbi.nlm.nih.gov/pmc/articles/PMC3396084/pdf/i1552-5775-9-3-38.pdf

21. Hickson M. Malnutrition and ageing. Postgrad Med J [Internet]. 2006 Jan;82(963):2-8. Available from: http://www.ncbi.nlm.nih.gov/pubmed/16397072

22. Zverev YP. Relationship between arm span and stature in Malawian adults. Ann Hum Biol. 2003;30(6):739-43.

23. Heymsfield SB, Peterson CM, Thomas DM, Heo M, Schuna JM. Why are there race/ethnic differences in adult body mass index-adiposity relationships? A quantitative critical review. Obes Rev. 2016 Mar;17(3):262-75. Available from: http://www.ncbi.nlm.nih.gov/pubmed/26663309

24. Borba de Amorim R, Coelho Santa Cruz MA, Borges de Souza-Júnior PR, Corrêa da Mota J, González H C. Stimating stature measurements applied on body mass index in the nutritional assessment of the elderly. Rev Chil Nutr. 2008;35:272-9. Available from: https://scielo.conicyt.cl/scielo.php? script=sci_arttext\&pid=S0717-75182008000400003

25. Arlappa N, Aatif Qureshi I, Philip Ravikumar B, Balakrishna N, Arbaab Qureshi M. Arm Span Is An Alternative To Standing Height For Calculation Of Body Mass Index (BMI) Amongst Older Adults. Jahan-mihan A, editor. Int J Nutr. 2016 Mar 28;2(1):12-24. Available from: http://openaccesspub.org/ijn/article/267

26. Pothirat C, Chaiwong W, Phetsuk N. Impact of direct substitution of arm span length for current standing height in elderly COPD. Int J Chron Obstruct Pulmon Dis. 2015 Jun 22;10(1):1173. Available from: http://www.dovepress.com/impact-of-direct-substitution-of-arm-span-length-for-current-standing-peerreviewed-article-COPD

27. Gomez F, Corchuelo J, Curcio CL, Calzada MT, Mendez F. SABE Colombia: Survey on Health, Well-Being, and Aging in Colombia - Study Design and Protocol. Curr Gerontol Geriatr Res. 2016;2016.

28. Reeves SL, Varakamin C, Henry CJ. The relationship between arm-span measurement and height with special reference to gender and ethnicity. Eur J Clin Nutr 1996 Jun ;50(6):398-400. Available from: http://www.ncbi.nlm.nih.gov/pubmed/8793422

\section{Tables}

Table 1. Study population, descriptive statistics for height and arm span by age, Bogota SABE study

\begin{tabular}{|l|l|l|l|l|l|l|l|l|}
\hline \multicolumn{4}{|l}{ Male } & \multicolumn{2}{l|}{ Female } \\
\hline Age group (years) & $\mathrm{n}$ & Height $(\mathrm{cm})$ & Arm span $(\mathrm{cm})$ & Difference & $\mathrm{n}$ & Height $(\mathrm{cm})$ & Arm span (cm) & Difference \\
\hline $60-64$ & 142 & $164.0 \pm 6.7$ & $165.7 \pm 8.0$ & $1.7 \pm 4.4^{* *}$ & 240 & $152.0 \pm 5.7$ & $153.0 \pm 6.0$ & $1.0 \pm 3.7^{* *}$ \\
\hline $65-69$ & 122 & $162.3 \pm 7.5$ & $164.4 \pm 8.5$ & $2.0 \pm 7.3^{*}$ & 215 & $149.8 \pm 6.0$ & $151.4 \pm 6.3$ & $1.6 \pm 3.5^{* *}$ \\
\hline $70-74$ & 102 & $161.4 \pm 5.8$ & $163.8 \pm 7.2$ & $2.4 \pm 5.2^{* *}$ & 183 & $149.5 \pm 6.1$ & $151.2 \pm 6.6$ & $1.7 \pm 3.7^{* *}$ \\
\hline $75-79$ & 87 & $161.7 \pm 6.7$ & $163.0 \pm 7.4$ & $1.3 \pm 3.3^{* *}$ & 134 & $148.5 \pm 7.0$ & $150.1 \pm 7.6$ & $1.5 \pm 6.8^{*}$ \\
\hline$\geq 80$ & 82 & $161.5 \pm 8.0$ & $163.3 \pm 9.1$ & $1.9 \pm 4.0^{* *}$ & 122 & $147.2 \pm 6.7$ & $150.3 \pm 6.7$ & $3.1 \pm 4.5^{* *}$ \\
\hline Total & 535 & $162.3 \pm 7.0$ & $164.2 \pm 8.1$ & $1.9 \pm 5.2^{* *}$ & 894 & $149.8 \pm 6.4$ & $151.4 \pm 6.6$ & $1.7 \pm 4.4^{* *}$ \\
\hline
\end{tabular}

$* \mathrm{p}<0.01{ }^{* *} \mathrm{p}<0.001$ obtained by paired t-test 
Table 2. Linear regression equations estimating height from arm span and correlations between height and arm span; stratified for sex and age categories

\begin{tabular}{|c|c|c|c|c|c|c|}
\hline Age group & Sex & $\mathrm{n}$ & Estimated Equation & Adjusted $\mathrm{R}^{2}$ & SEE & Spearman (Rho) Correlation \\
\hline \multirow[t]{2}{*}{$60-64$} & Male & 142 & $\mathrm{H}=48.68+(0.69 * \mathrm{AS})$ & 0.69 & 3.72 & 0.86 \\
\hline & Female & 240 & $\mathrm{H}=36.67+(0.75 * \mathrm{AS})$ & 0.64 & 3.39 & 0.78 \\
\hline \multirow[t]{2}{*}{$65-69$} & Male & 122 & $\mathrm{H}=77.35+(0.52 * \mathrm{AS})$ & 0.34 & 6.09 & 0.80 \\
\hline & Female & 215 & $\mathrm{H}=28.93+(0.79 * \mathrm{AS})$ & 0.69 & 3.28 & 0.84 \\
\hline \multirow[t]{2}{*}{$70-74$} & Male & 102 & $\mathrm{H}=77.30+(0.56 * \mathrm{AS})$ & 0.48 & 4.14 & 0.76 \\
\hline & Female & 183 & $\mathrm{H}=33.05+(0.77 * \mathrm{AS})$ & 0.69 & 3.34 & 0.84 \\
\hline \multirow[t]{2}{*}{$75-79$} & Male & 87 & $\mathrm{H}=30.61+(0.80 * \mathrm{AS})$ & 0.79 & 3.02 & 0.86 \\
\hline & Female & 134 & $\mathrm{H}=69.94+(0.52 * \mathrm{AS})$ & 0.32 & 5.74 & 0.68 \\
\hline \multirow[t]{2}{*}{$\geq 80$} & Male & 82 & $\mathrm{H}=31.62+(0.79 * \mathrm{AS})$ & 0.81 & 3.51 & 0.90 \\
\hline & Female & 122 & $\mathrm{H}=30.46+(0.78 * \mathrm{AS})$ & 0.60 & 4.23 & 0.76 \\
\hline \multirow[t]{2}{*}{ Total } & Male & 535 & $\mathrm{H}=52.61+(0.67 * \mathrm{AS})$ & 0.60 & 4.43 & 0.84 \\
\hline & Female & 894 & $\mathrm{H}=37.42+(0.74 * \mathrm{AS})$ & 0.59 & 4.04 & 0.80 \\
\hline
\end{tabular}

Regression equation is $\mathrm{y}=\mathrm{a}+\mathrm{bx}$. Dependent variable $=$ Height as $\mathrm{y}$; Independent variable=Arm Span (AS) as $\mathrm{x}$. In the equation, $\mathrm{a}=\mathrm{constant}$ and $b=$ regression coefficient for arm span. SEE=standard error of estimate is the root mean standard error. All estimated equations and all correlations have $\mathrm{p}<.0001$

\section{Figures}




\section{Correlation between Arm span and Height}

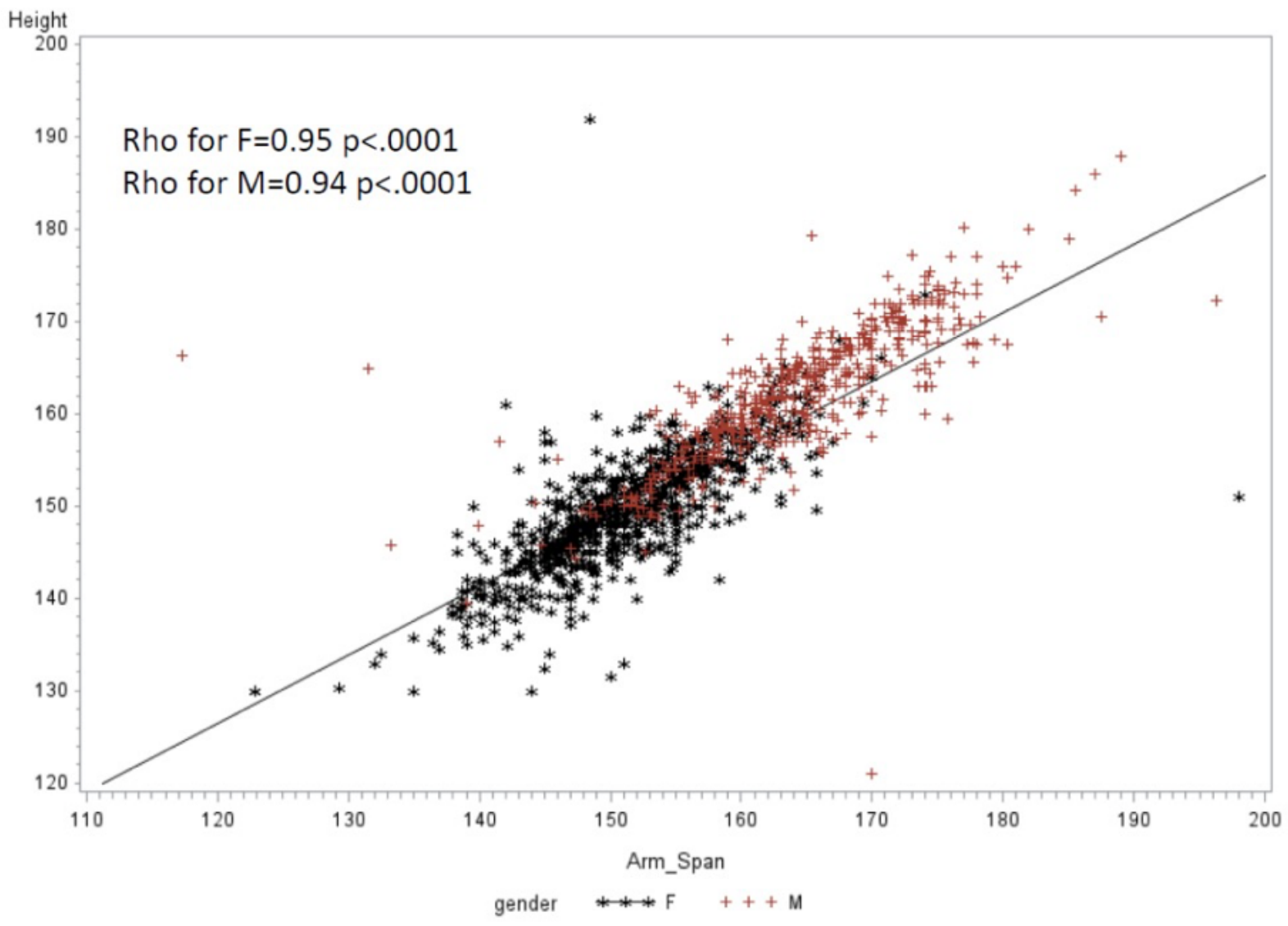

Figure 1

Sex-stratified Scatter-plot Between Arm Span and Height, showing Spearman`s Rho

Bland-Altman Plot

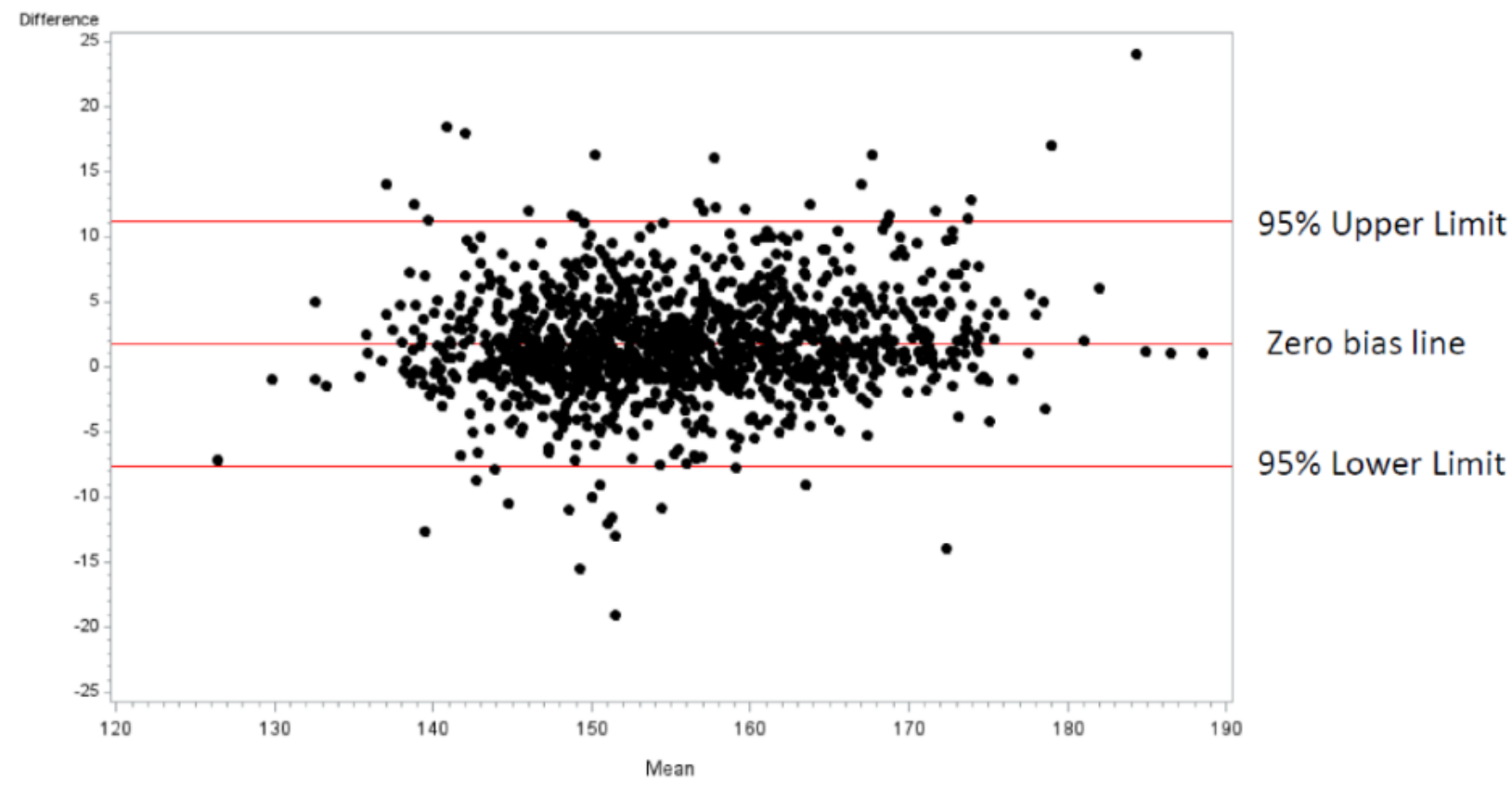

Differences and Means (Height and Arm span)

Figure 2 
Bland-Altman Plot for Height and Arm Span

Page $9 / 9$ 